\title{
Effects of Tempering Temperature on the Microstructure and Mechanical Properties of T92 Heat-Resistant Steel
}

\author{
Dandan Zhao ${ }^{1} \oplus$, Shenghua Zhang ${ }^{1}$, Hai Zhang ${ }^{1}$, Shilei Li ${ }^{1} \oplus$, Huifang Xiao ${ }^{2}$, Yanli Wang ${ }^{1, *}$ \\ and Xitao Wang ${ }^{3,4, *(1)}$ \\ 1 State Key Laboratory for Advanced Metals and Materials, University of Science and Technology Beijing, \\ Beijing 100083, China; ddzhao1990@163.com (D.Z.); zshzai@163.com (S.Z.); \\ zhangxianhai2017@163.com (H.Z.); lishilei@ustb.edu.cn (S.L.) \\ 2 School of Mechanical Engineering, University of Science and Technology Beijing, Beijing 100083, China; \\ huifangxiao@ustb.edu.cn \\ 3 Collaborative Innovation Center of Steel Technology, University of Science and Technology Beijing, Beijing \\ 100083, China \\ 4 Shandong Provincial Key Laboratory for High Strength Lightweight Metallic Materials, Advanced Materials \\ Institute, Qilu University of Technology (Shandong Academy of Science), Jinan 250353, China \\ * Correspondence: wangyl@ustb.edu.cn (Y.W.); xtwang@ustb.edu.cn (X.W.); Tel.: +86-135-2113-0742 (Y.W.); \\ +86-139-1029-7623 (X.W.)
}

Received: 21 January 2019; Accepted: 3 February 2019; Published: 7 February 2019

\begin{abstract}
T92 heat-resistant steel is among the most promising candidate materials for structural components in the Generation IV (GEN-IV) reactors. The effects of tempering temperature on the microstructure and mechanical properties of the T92 steel were studied. The microstructural evolution of the T92 steel subjected to various temperatures of the tempering process were investigated using scanning electron microscopy (SEM), transmission electron microscopy (TEM), and synchrotron radiation X-ray diffraction (SR-XRD). The mechanical properties of Vickers hardness, tensile test, and impact test were also investigated. The results showed that the grain size of the prior austenite does not significantly change during the tempering process, while the width of the martensite lath and the size of the carbide precipitates increased with increasing tempering temperature. The hardness and yield strength of the T92 steel decreased, and the plasticity and impact energy increased with increasing tempering temperature. Coarsening of the carbide precipitates during the tempering process was considered to be the dominant factor that reduced the yield strength in the T92 steel.
\end{abstract}

Keywords: T92 heat-resistant steels; tempering temperature; mechanical properties; strengthening effect; synchrotron radiation $\mathrm{X}$-ray diffraction

\section{Introduction}

T92 heat-resistant steel has excellent high temperature strength, high thermal conductivity, a low expansion rate, and good corrosion resistance, and it is widely used in the pipes for main steam and reheat steam in ultra-supercritical units [1]. T92 steel is also considered as one of the most promising candidate materials for structural components in the Generation IV (GEN-IV) reactors because of its excellent radiation resistance performance [2,3].

T92 heat-resistant steel has a microstructure of tempered lath martensite and precipitates, including $\mathrm{M}_{23} \mathrm{C}_{6}$ carbides, $\mathrm{MX} \mathrm{V} / \mathrm{N}$ carbonitrides, and high density of dislocations in matrix [4-6], where all of them can contribute to the strength of the material. The main microstructural evolution of T92 steel during long-term thermal aging and service includes the coarsening of the lath 
martensite, decreasing of dislocation density, and the growth of precipitates $\left(\mathrm{M}_{23} \mathrm{C}_{6}\right.$ carbides and Laves phases) [6-9]. The microstructure evolution results in the deterioration of the mechanical properties of T92 steel. Heat treatment had important effects on both the microstructure $[5,10,11]$ and mechanical properties [5,11] of 9Cr F/M steels, and it has been reported that the key to improve the high temperature properties of T92 steel is to precipitate enough dispersed carbonitrides in the pre-treatment stage [12], which can remain stable during long-term high temperature service. The common heat treatment of T92 steel includes a normalizing process, following tempering process [13]. During the normalizing process, the microstructure firstly transforms to austenite and then it transforms to quenched martensite during the subsequent air cooling process [5,14]. The quenched martensite transforms into tempered martensite during the tempering process [3]. As the last process of heat treatment, the tempering process can significantly affect both the microstructure and the mechanical properties of the steel, including the recovery of martensitic lath, reduction of dislocation density, reduction of hardness and yield strength, etc. $[5,15,16]$. The understanding of the effects of the various microstructural evolution during tempering on the mechanical properties is important to both the optimum design of the materials and the industrial application.

In this work, the microstructure and mechanical properties of the T92 steel tempered at several different temperatures were investigated. Carbide precipitates in the T92 steel were observed by scanning electron microscopy (SEM) and quantitatively analyzed using synchrotron radiation X-ray diffraction (SR-XRD). The martensite lath and dislocation were observed using transmission electron microscopy (TEM) and dislocation density was quantitatively analyzed using SR-XRD. Tensile, impact, and hardness tests were carried out on the T92 steel. The relationship between the microstructure and mechanical properties of the T92 steel was analyzed.

\section{Materials and Methods}

The investigated T92 steel was received as hot-rolled tubes in normalized and tempered conditions from Baoshan Iron \& Steel (Shanghai, China). The size of the as-received tube was $50.80 \mathrm{~mm}$ in diameter and $11.50 \mathrm{~mm}$ in thickness. The chemical composition is listed in Table 1, and the microstructure of the as-received T92 steel can be found in our previous work in Reference [6].

Table 1. Chemical composition (wt.\%) of the T92 heat-resistant steel.

\begin{tabular}{ccccccccccccccc}
\hline Elements & $\mathbf{C}$ & $\mathbf{S i}$ & $\mathbf{M n}$ & $\mathbf{P}$ & $\mathbf{S}$ & $\mathbf{C r}$ & $\mathbf{W}$ & $\mathbf{M o}$ & $\mathbf{N i}$ & $\mathbf{V}$ & $\mathbf{N b}$ & $\mathbf{B}$ & $\mathbf{N}$ & $\mathbf{F e}$ \\
\hline T92 steel & 0.12 & 0.2 & 0.53 & 0.017 & 0.0008 & 8.86 & 1.65 & 0.38 & 0.20 & 0.20 & 0.048 & 0.0024 & 0.046 & Balance \\
\hline
\end{tabular}

The equipment for the heat-treatment was a box-type resistance furnace and the heating atmosphere was air. Firstly, all of the as-received T92 steel tubes were put into the furnace at one time and normalized at $1060{ }^{\circ} \mathrm{C}$ for $30 \mathrm{~min}$, followed by air cooling to ensure the same normalizing heat treatment for each tube. Then they were separately tempered in the furnace at $715^{\circ} \mathrm{C}, 740{ }^{\circ} \mathrm{C}, 765{ }^{\circ} \mathrm{C}$, $790{ }^{\circ} \mathrm{C}$, and $815^{\circ} \mathrm{C}$ for $30 \mathrm{~min}$, followed by air cooling. The heating rate of both the normalizing and tempering were $10^{\circ} \mathrm{C} / \mathrm{min}$. All of the samples were cut from the tempered tubes along the same direction to eliminate the influence of crystal anisotropy. Samples that were $10 \times 10 \times 5 \mathrm{~mm}^{3}$ in size were cut from the T92 tubes for microstructure observation. The samples were mechanically grounded and polished, and then they were chemically etched with a solution of $5 \mathrm{~g}$ ferric trichloride $+100 \mathrm{~mL}$ hydrochloric acid $+100 \mathrm{~mL}$ ethanol $+100 \mathrm{~mL}$ deionized water at room temperature (RT). The surfaces of the samples were characterized by a ZEISS SUPRA55 SEM (Carl Zeiss Microscopy Ltd, Cambridge, UK) equipped with a Schottky field emission electron source, and the resolution of the SEM was 1.0 $\mathrm{nm}$ under the accelerate voltage of $15 \mathrm{kV}$. More details about the microstructure were characterized by a field emission high resolution a Tecnai G2 F30 TEM (FEI Inc., Hillsborough, OR, USA), with an accelerate voltage of $300 \mathrm{kV}$ and resolution of $0.205 \mathrm{~nm}$. The TEM specimens were cut as discs that were $3 \mathrm{~mm}$ in diameter and mechanically ground to $50 \mu \mathrm{m}$ in thickness, and they were finished by 
electrochemical polishing in an ethanol solution of $10 \%$ perchloric acid at $-30{ }^{\circ} \mathrm{C}$ using a twin-jet polishing apparatus.

Phase identification in all the T92 samples with different heat treatment states was carried out on a beam-line $13 \mathrm{~W}$ at the Shanghai Synchrotron Radiation Facility (SSRF) using an energy of $\sim 42 \mathrm{keV}$ (corresponding to a wavelength of $\sim 0.0298 \AA$ ). The hardness was measured using a Wolpert- 401 MVD microhardness tester (Wolpert Wilson Instruments, Norwood, NJ, US) with a load of $200 \mathrm{~g}$ and a dwell time of $10 \mathrm{~s}$. The impact properties of the T92 steel were tested using the standard V-notch specimens on a Zwick RKP-450 (Zwick Inc., Ulm-Einsingen, Germany) test machine. Tensile tests using the rod specimens that were $5 \mathrm{~mm}$ in diameter and $25 \mathrm{~mm}$ in gauge length, were carried out on a DDL-50 electronic universal testing machine with a strain rate of $0.525 \mathrm{~mm} / \mathrm{min}$ at RT. The fractographies of the tensile and impact specimens were analyzed using SEM.

\section{Results}

\subsection{Microstructure Observation}

Figure 1 shows the SEM observations of the T92 heat-resistant steel normalized at $1060{ }^{\circ} \mathrm{C}$ and tempered at different temperatures. Both the prior austenite grain boundaries (PAGBs) and the martensite lath boundaries (MLBs) could be observed in all the samples. With increasing tempering temperature, no significant change in the grain size of the primary austenite was observed, while the martensite laths became clearer and more uniform. It was reported that the grain size of the prior austenite was related to normalizing heat treatment [11], increasing with the increasing temperature during the normalizing heat treatment, while the normalizing temperature was unchanged in this work. The mean size of the prior austenite grains and the length of the martensite laths are shown in the Table 2, and none of them had an obvious correlation with the tempering temperature. While the volume fraction of the precipitates increased with an increasing tempering temperature. The carbide precipitates distributed along the PAGBs were observed in all the samples, while the precipitation of $\mathrm{M}_{23} \mathrm{C}_{6}$ along the MLBs were obvious only when the tempering temperature reached $765^{\circ} \mathrm{C}$ or higher. This was because the quenched martensite had not been fully recovered at a low tempering temperature of $715^{\circ} \mathrm{C}$ and $740{ }^{\circ} \mathrm{C}$, and the supersaturated solute atoms could not be fully and uniformly dissolved from the MLBs to form the carbides.

Table 2. Grain size of the T92 heat-resistant steels tempered at different temperatures.

\begin{tabular}{cccccc}
\hline Tempering Temperature $\left({ }^{\circ} \mathbf{C}\right)$ & $\mathbf{7 1 5}$ & $\mathbf{7 4 0}$ & $\mathbf{7 6 5}$ & $\mathbf{7 9 0}$ & $\mathbf{8 1 5}$ \\
\hline Prior austenite grain size $(\mu \mathrm{m})$ & $20.1 \pm 5.3$ & $19.7 \pm 6.1$ & $19.9 \pm 6.3$ & $20.2 \pm 7.9$ & $19.8 \pm 5.5$ \\
Length of martensite lath $(\mu \mathrm{m})$ & $9.8 \pm 4.1$ & $10.7 \pm 3.9$ & $9.9 \pm 3.6$ & $11.6 \pm 5.1$ & $11.2 \pm 3.7$ \\
Width of martensite lath $(\mathrm{nm})$ & $348 \pm 98$ & $407 \pm 96$ & $437 \pm 78$ & $489 \pm 131$ & $495 \pm 117$ \\
\hline
\end{tabular}

TEM micrographs of the samples tempered at $740{ }^{\circ} \mathrm{C}$ and $790{ }^{\circ} \mathrm{C}$ are shown in Figure 2. The details of the martensite laths, dislocation structure, and carbide size and distribution in the T92 heat-resistant steel are clearly seen. The width of the martensite lath in the sample tempered at $740{ }^{\circ} \mathrm{C}$ was significantly less than that in the sample tempered at $790{ }^{\circ} \mathrm{C}$, while the dislocation density in the sample tempered at $740{ }^{\circ} \mathrm{C}$ was much higher. The significantly greater recovery of quenched martensite in the sample tempered at $790{ }^{\circ} \mathrm{C}$ resulted in a larger width of the martensite laths, and dislocation rearrangement and annihilation were more sufficient in this process. The mean width of the martensite lathes of different temperature tempered samples is shown in Table 2. Carbides precipitates and dispersed nano-sized MX phases could be observed in these two samples. No obvious changes of the MX were observed. The precipitates of $\mathrm{M}_{23} \mathrm{C}_{6}$ in the sample tempered at $790{ }^{\circ} \mathrm{C}$ had significantly larger sizes and a higher density than the precipitates in the sample tempered at $740{ }^{\circ} \mathrm{C}$. The results were in good agreement with the SEM observations in Figure 1. 

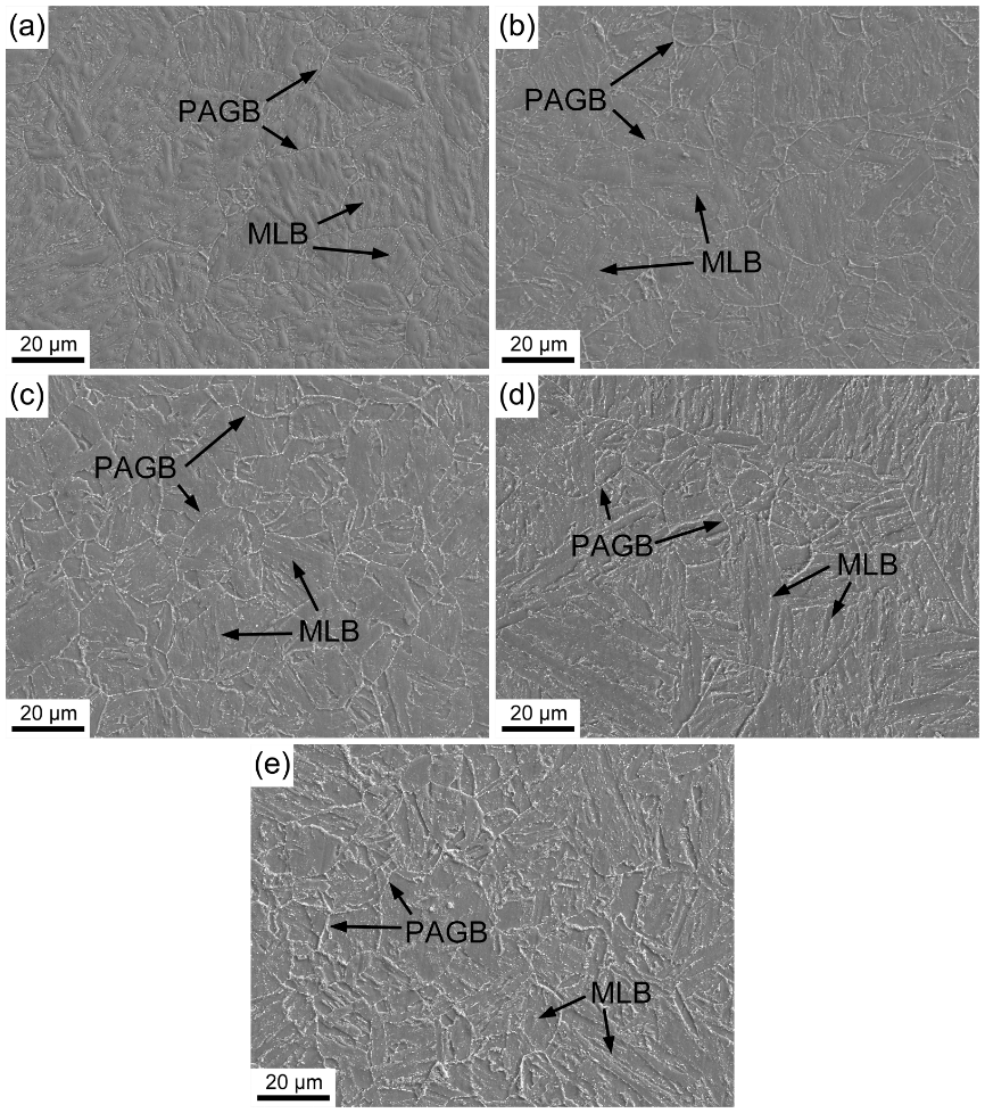

Figure 1. Scanning electron microscopy (SEM) micrographs of the T92 heat-resistant steel tempered at different temperatures: (a) $715^{\circ} \mathrm{C}$, (b) $740{ }^{\circ} \mathrm{C}$, (c) $765^{\circ} \mathrm{C}$, (d) $790{ }^{\circ} \mathrm{C}$, and (e) $815^{\circ} \mathrm{C}$.
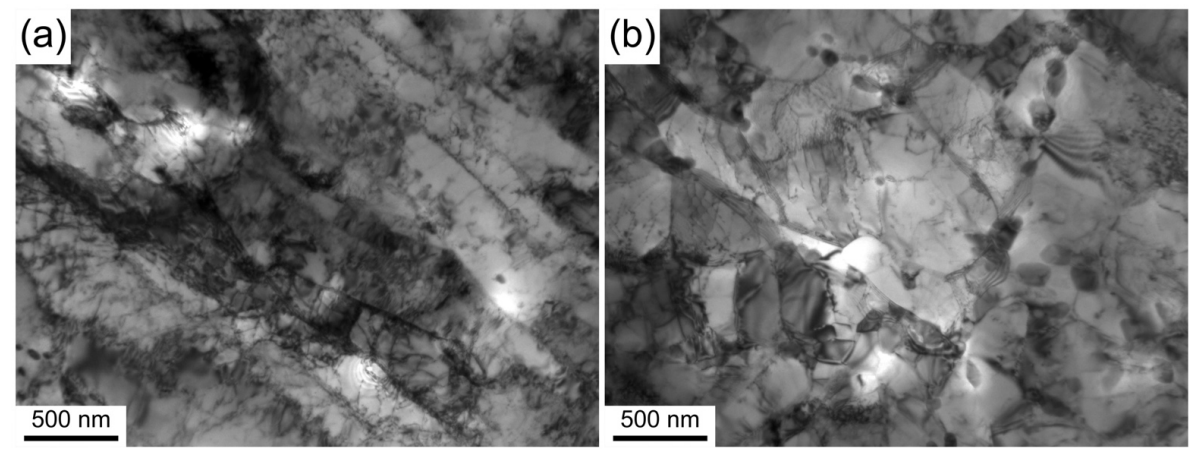

Figure 2. Transmission electron microscopy (TEM) micrographs of the T92 heat-resistant steel tempered at (a) $740{ }^{\circ} \mathrm{C}$ and (b) $790^{\circ} \mathrm{C}$.

\subsection{Synchrotron Radiation X-ray Diffraction}

SR-XRD experiments were carried out on T92 steel samples tempered at different temperatures and the results are shown in Figure 3. The six strong peaks for the Fe matrix are marked in the figure and the weak peaks are diffractions of the precipitates. The Fe (200) peak (marked with red arrows) was chosen to analyze the change of dislocation density in the T92 samples tempered at different temperatures. The $\mathrm{M}_{23} \mathrm{C}_{6}$ (420) peak was chosen to investigate the change of carbide precipitates because the peak was relatively far away from the peaks of the matrix and it had a higher diffraction intensity. The $d$-spacing values of $\mathrm{Fe}(200)$ and $\mathrm{M}_{23} \mathrm{C}_{6}$ (420) were calculated to be $1.4332 \AA$ and 2.3835 $\AA$, respectively. Pseudo-Voigt function, the linear combination of Gaussian function and Lorentzian function, was used to fit the XRD spectrums. 


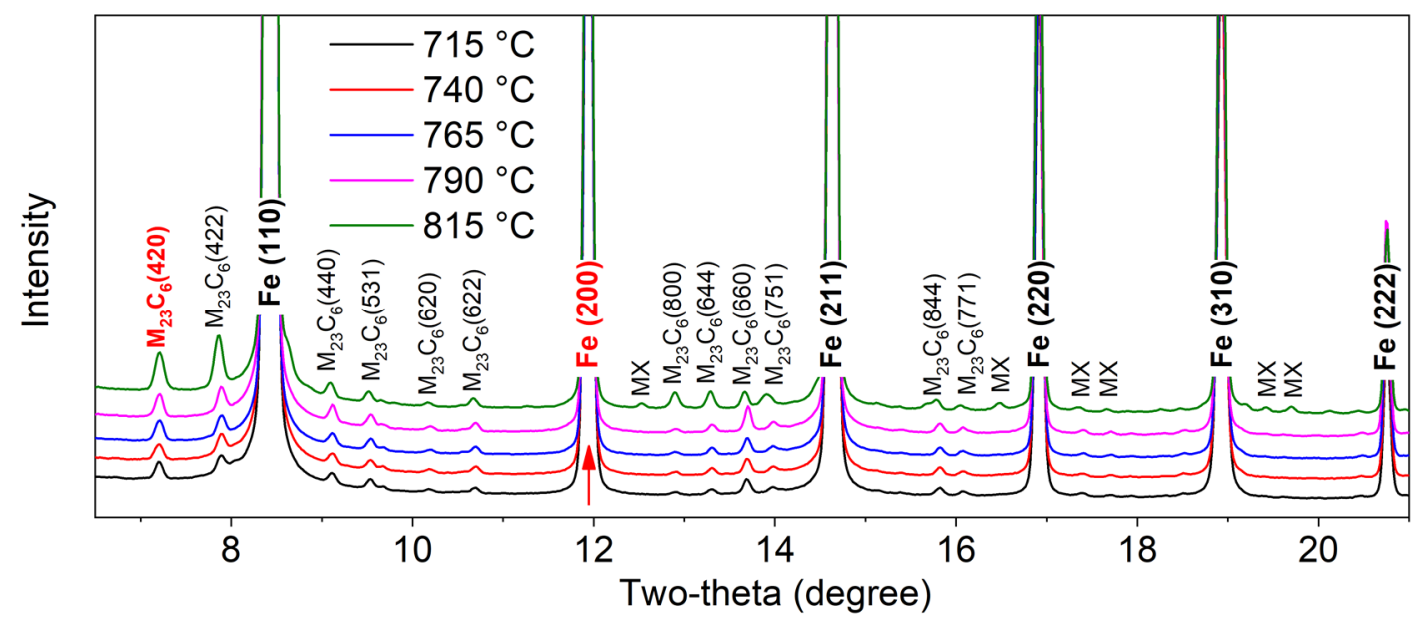

Figure 3. Synchrotron radiation X-ray diffraction (SR-XRD) spectrum of the P92 heat-resistant steel tempered at different temperatures.

Figure 4a shows the evolution of the full wave at half maximum (FWHM) of the Fe (200) peak as a function of the tempering temperature for the T92 heat-resistant steel. The significant decrease of the FWHM in the range from $715^{\circ} \mathrm{C}$ to $790{ }^{\circ} \mathrm{C}$ was observed with the increasing tempering temperature, while FWHM remained unchanged when the tempering temperature further increased from $790{ }^{\circ} \mathrm{C}$ to $815{ }^{\circ} \mathrm{C}$. According to the Williamson-Hall method, the value of the FWHM is closely related to the dislocation density and the average crystallite size (mean block width for martensitic steel). The changes of the FWHM with tempering temperature were consistent with the microstructural evolution, e.g., coarsening of martensite laths and the decrease of dislocation density observed using TEM in the samples tempered at $740{ }^{\circ} \mathrm{C}$ and $790{ }^{\circ} \mathrm{C}$, as shown in Figure 2. The density of dislocations can be calculated from the FWHM results shown in Figure 4a using the following equation:

$$
\Delta K=0.9 / D+\left(\pi M_{\mathrm{d}}^{2} b_{\mathrm{d}}^{2} / 2\right)^{1 / 2} \rho^{1 / 2}\left(K C^{1 / 2}\right)
$$

where $K=2 \sin \theta / \lambda$, and $\theta$ is the diffraction angle and $\lambda$ is the wavelength of $X$-ray; $\Delta K=2 \cos \theta \Delta \theta / \lambda$, $\Delta \theta$ is half of the FWHM of the diffraction peak; $D$ is the mean grain size; $M_{\mathrm{d}}$ is an adjustable parameter depending on the effective outer cut-off radius of the dislocations, and $M_{d}=2$ was used for all the samples according to Reference [17]. $b_{\mathrm{d}}$ is the Burgers vector of dislocations: there are $a_{0}\langle 100\rangle$ and $1 / 2 a_{0}\langle 111\rangle$ types of dislocations in the F/M T92 steel, $b_{\mathrm{d}}^{2}=0.875$ by assuming that each type of dislocations accounts for $50 \%$ in the material in this work; $\rho$ is the density of dislocations; $C$ is the dislocation contrast factor and it was taken as 0.283 for $\mathrm{Fe}(200)$ plane by assuming $50 \%$ edge dislocations plus 50\% screw dislocations in the material, which has been confirmed to be more fitted with the experiment results by Wang et al. [18].The tempering temperature dependence of the dislocation density calculated by the FWHM results of the Fe (200) peak is shown in Figure 4b. The dislocation density in this work was in the same order of magnitude as reported in Reference [19]. The variation trend of the dislocation density was consistent with that of the FWHM results, which powerfully and directly proved the TEM results observed in the samples tempered at $740{ }^{\circ} \mathrm{C}$ and $790{ }^{\circ} \mathrm{C}$. 

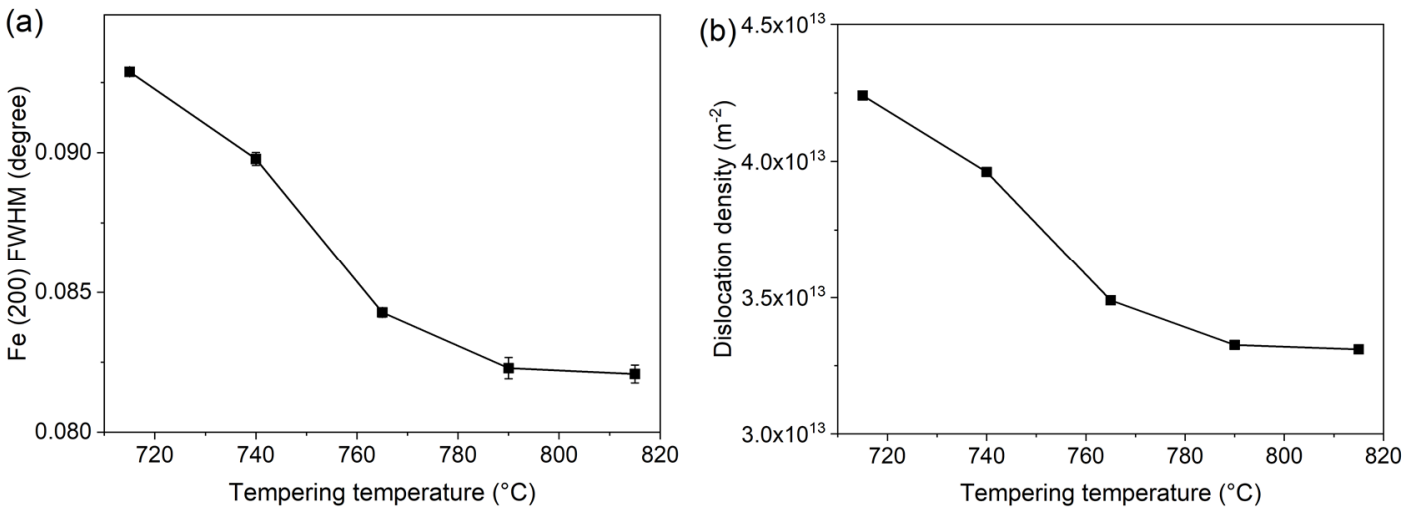

(c)

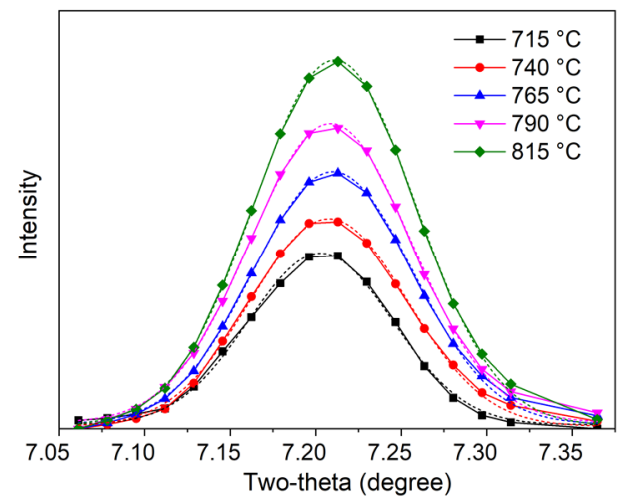

(d)

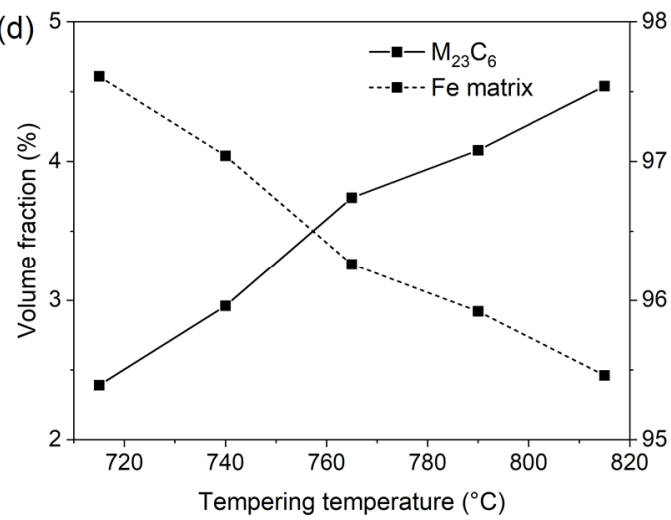

Figure 4. (a) Fitted full wave at half maximum (FWHM) of the Fe (200) peak, (b) calculated dislocation density in the Fe matrix, (c) the peak intensity of the $\mathrm{M}_{23} \mathrm{C}_{6}$ (420) plane, and (d) volume fractions of the Fe matrix and $\mathrm{M}_{23} \mathrm{C}_{6}$ phase estimated by integrated intensities of diffraction peaks in the T92 steel tempered at different temperatures characterized by SR-XRD.

Figure $4 \mathrm{c}$ shows the peak profiles of $\mathrm{M}_{23} \mathrm{C}_{6}$ (420). The diffraction intensity increases obviously with the increasing tempering temperature. The volume fractions of the precipitates can be quantitatively compared through the sum of the integral intensity of all the diffraction peaks of each phase [20]. The integral intensity of $\mathrm{M}_{23} \mathrm{C}_{6}$ (420) increases with the increasing tempering temperature, indicating that the volume fraction of the carbide precipitates increases significantly. The volume fractions of the martensite matrix and the $\mathrm{M}_{23} \mathrm{C}_{6}$ phase were estimated through the integrated intensities of the diffraction peaks according to Reference [21] by assuming that the total diffraction contribution of the phases was the sum of the $\mathrm{BCC}$ martensite matrix and the $\mathrm{M}_{23} \mathrm{C}_{6}$ precipitates. The MX phase was not considered because its peaks were too weak. The volume fraction evolutions of the martensite matrix and the $\mathrm{M}_{23} \mathrm{C}_{6}$ phase in the T92 steels tempered at different temperatures are shown in Figure $4 \mathrm{~d}$. The volume fraction of $\mathrm{M}_{23} \mathrm{C}_{6}$ in the T92 heat-resistant steel tempered at $815^{\circ} \mathrm{C}$ was estimated as about two times that in the steel tempered at $715^{\circ} \mathrm{C}$.

\subsection{Mechanical Properties}

The Vickers hardness of the T92 steel tempered at different temperatures are shown in Figure 5a. The values of hardness showed a notable decreasing trend when the tempering temperature rose, which was mainly due to the reduction of the dislocation density. Figure $5 \mathrm{~b}$ shows the RT impact energy of the T92 heat-resistant steel tempered at different temperatures. With an increasing tempering temperature, the impact energy of the material showed an upward trend. The impact energy significantly increased from $57 \mathrm{~J}$ for the sample tempered at $715^{\circ} \mathrm{C}$ to $193 \mathrm{~J}$ for the sample tempered at $815^{\circ} \mathrm{C}$. The impact energy increased rapidly with the increasing tempering temperature in the range from $715^{\circ} \mathrm{C}$ to 765 ${ }^{\circ} \mathrm{C}$, and the increase became slower at higher tempering temperatures $\left(790^{\circ} \mathrm{C}\right.$ and $\left.815^{\circ} \mathrm{C}\right)$. The fracture 
surfaces of the impact samples were observed by SEM, as shown in Figure 6. The sample tempered at $715{ }^{\circ} \mathrm{C}$ shows a mixed characteristic of dimples and brittle cracks. With an increasing tempering temperature, the brittle features decreased rapidly, and the area percent of dimples increased. The fracture surfaces of the samples tempered over $765^{\circ} \mathrm{C}$ presented complete ductile facture with dimples where the size and depth also increased with an increasing tempering temperature.
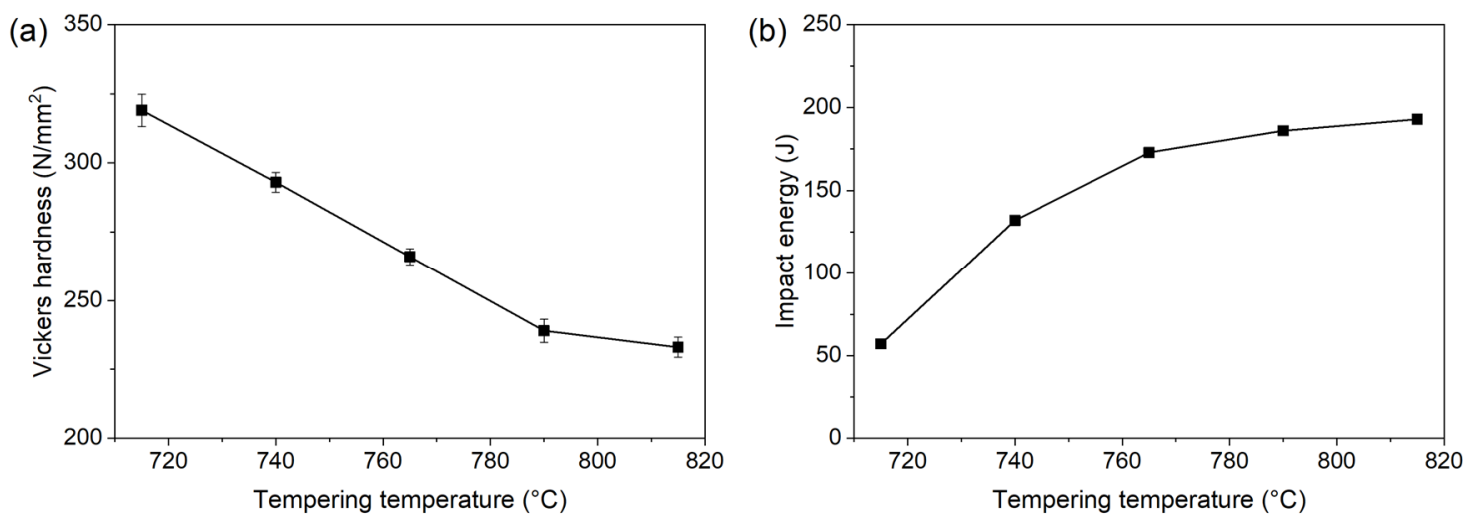

Figure 5. Tempering temperature dependence of (a) Vickers hardness and (b) room temperature (RT) impact energy of the T92 heat-resistant steel.
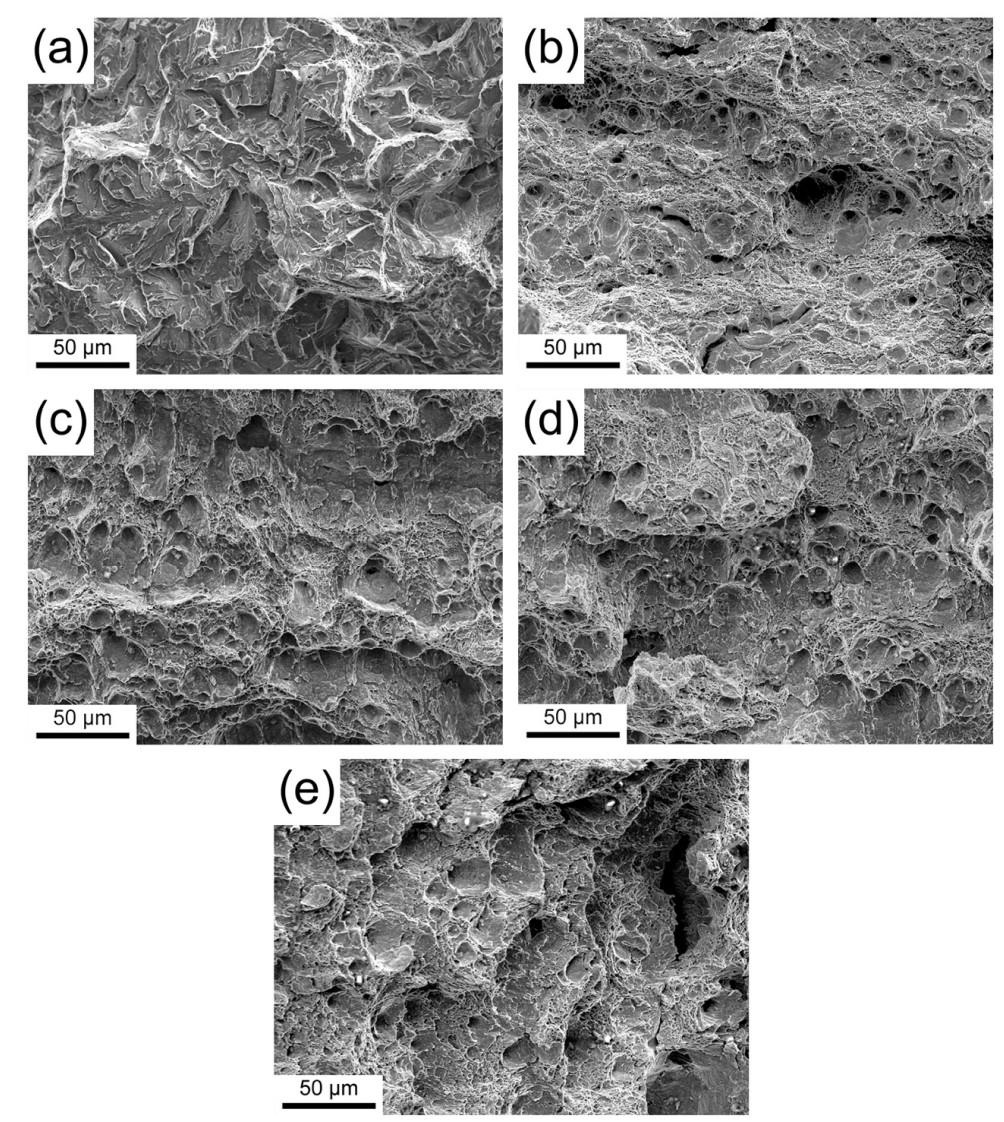

Figure 6. SEM micrographs of the impact fracture surfaces of the T92 heat-resistant steel samples tempered at different temperatures: (a) $715^{\circ} \mathrm{C}$, (b) $740{ }^{\circ} \mathrm{C}$, (c) $765^{\circ} \mathrm{C}$, (d) $790{ }^{\circ} \mathrm{C}$, and (e) $815^{\circ} \mathrm{C}$.

Figure 7 shows the RT tensile properties of the T92 heat-resistant steel tempered at different temperatures. When the tempering temperature was lower than $790{ }^{\circ} \mathrm{C}$, the yield strength and tensile strength decreased rapidly with the increasing tempering temperature. When the tempering temperature was higher than $790^{\circ} \mathrm{C}$, the trend of the decline tended to be gentle. The variation trend 
of elongation after fracture was opposite to that of the strength, and the sample tempered at $815^{\circ} \mathrm{C}$ showed the best plasticity. It should be noted that the increase of elongation at the stage between $740{ }^{\circ} \mathrm{C}$ and $765{ }^{\circ} \mathrm{C}$ was significantly higher than other tempering temperature ranges, indicating that the plasticity of the material had changed a lot in this temperature range. Plasticity was closely related to the degree to which dislocation motion and material could coordinate before fracture, where the rapid increase of elongation was due to the rapid reduction of dislocation density (as shown in Figure $4 b$ ) at this stage.

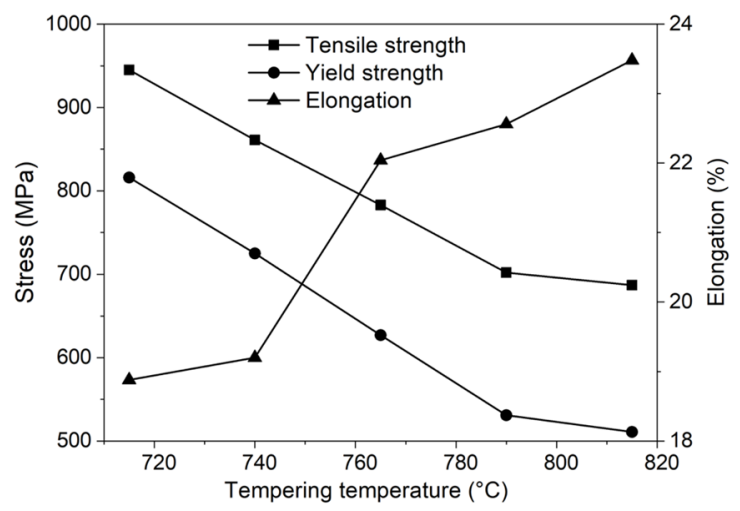

Figure 7. Tempering temperature dependence of the RT tensile properties of the T92 heat-resistant steel.

The tensile fracture surfaces of the T92 samples tempered at different temperatures were also observed by SEM, as shown in Figure 8. The fracture surfaces of the samples tempered below $765{ }^{\circ} \mathrm{C}$ demonstrated the mixed morphologies of both ductile dimples and brittle cracks. The samples tempered at $790^{\circ} \mathrm{C}$ and $815^{\circ} \mathrm{C}$ showed typical ductile fracture surfaces with various sizes of dimples. Besides the large size of the brittle fracture cracks marked with red lines, brittle features with small sizes were also observed and some of them were marked with red circles in Figure 8a-c. Some dimples on the fracture surfaces for all the temperature tempered samples were marked with white arrows in Figure 8, and the percentage of dimples increased with the increasing tempering temperature. The dimples observed in the $715^{\circ} \mathrm{C}$ tempered sample had smaller sizes and lower depth, which showed the worst plasticity. Obvious increases of both the size and number of dimples were observed in the T92 sample tempered at $765^{\circ} \mathrm{C}$ compared to the one tempered at $740{ }^{\circ} \mathrm{C}$, leading to the fast increase of elongation when tempering temperature increased from $740{ }^{\circ} \mathrm{C}$ to $765^{\circ} \mathrm{C}$. The dimples observed in the $790{ }^{\circ} \mathrm{C}$ and $815^{\circ} \mathrm{C}$ tempered samples were deeper and more uniform. The fracture surface morphologies indicated that the plasticity of the T92 heat-resistant steel was improved with increasing tempering temperature, which was consistent with the results of the tensile test. 

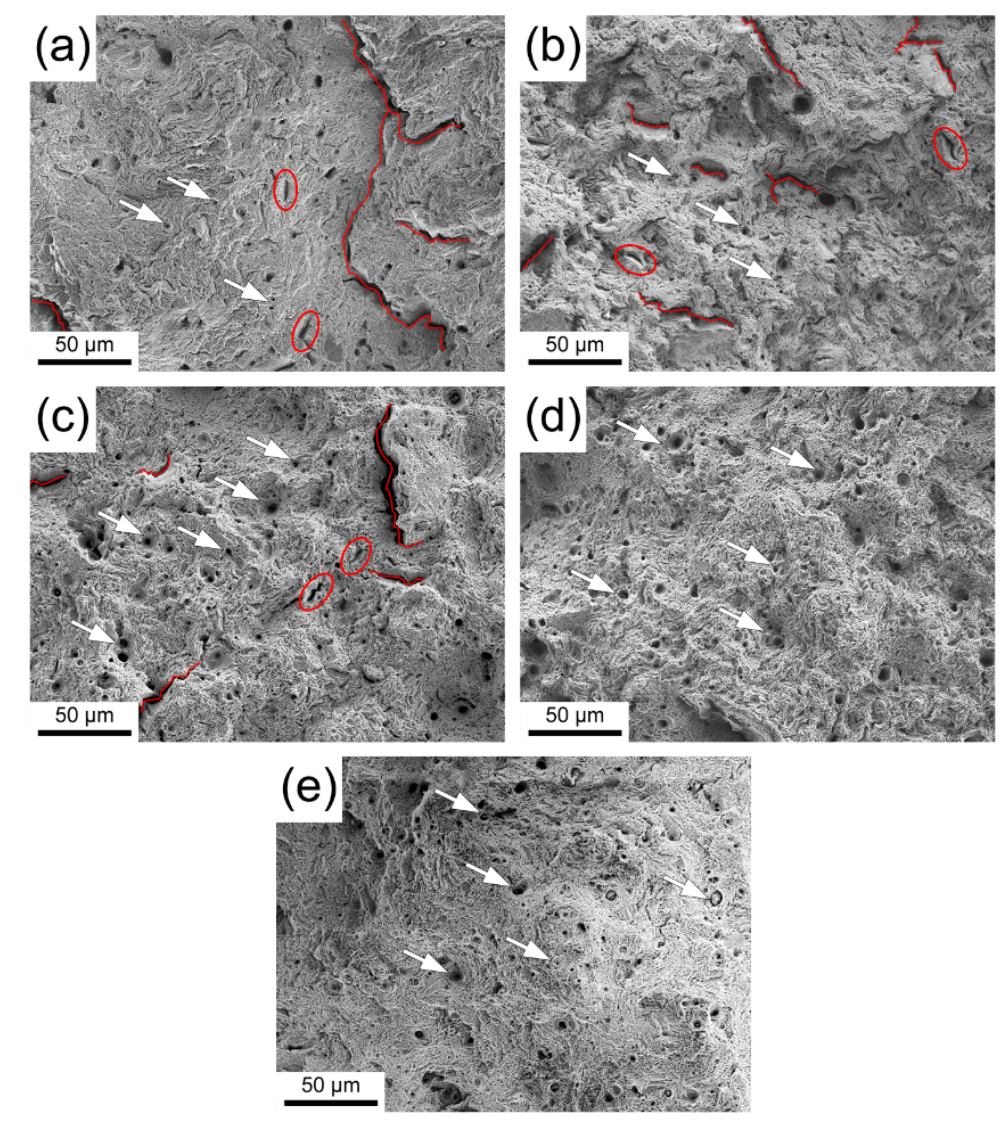

Figure 8. SEM micrographs of the tensile fracture surfaces of the T92 heat-resistant steel samples tempered at different temperatures: (a) $715^{\circ} \mathrm{C}$, (b) $740{ }^{\circ} \mathrm{C}$, (c) $765^{\circ} \mathrm{C}$, (d) $790{ }^{\circ} \mathrm{C}$, and (e) $815^{\circ} \mathrm{C}$.

\section{Discussion}

The microstructural evolution and changes of hardness, impact energy, and tensile properties of the T92 heat-resistant steel tempered at different temperatures were carried out. The results indicated that both the microstructure and the mechanical properties had a strong dependence on tempering temperature. All of the microstructural changes, including width of the martensite lath, dislocation density, and precipitation of carbides, directly affected the mechanical properties of the materials.

A prior austenite grain (PAG) usually contains 3-5 packets in one PAG, leading to the similar tendency of packet and PAG size values. However, the number of blocks contained in one packet varies, which leads to a dissimilar tendency of block width values to that of the PAG size values. The refinement of the martensitic microstructure, especially blocks, could induce an increase in the yield strength [22]. The samples tempered at different temperatures were firstly treated with the same normalizing process. Thus, the samples with similar PAG size had different martensite lath widths and block widths induced by the various tempering temperatures. The precipitates can also play a key role in affecting the yield strength, and the precipitation strengthening effect becomes weakened after the coarsening of particles and the increasing of inter-particle spacing [14]. Wang et al. [23] suggested that $\mathrm{M}_{23} \mathrm{C}_{6}$ precipitates can effectively strengthen the material by impeding the dislocation movement. Significant coarsening of carbides with increasing tempering temperature was observed in this work, while the MX precipitates were stable in size and volume fraction. Dislocation density also had an unneglectable effect on the mechanical properties of the materials according to the dislocation-based hardening law in Reference [24]. The increase of the dislocation density leads to the increments of hardness and strength. The XRD and TEM results proved the differences in dislocation density among the samples tempered at different temperatures. In general, the microstructures with different lath 
widths, carbides sizes, and dislocation densities resulted in the different mechanical performances of the T92 samples tempered at different temperatures.

Under impact loading, when the local stress exceeds the yield strength of the matrix, the plastic deformation zone will appear at the crack tip. The sample with smaller hardness usually has a larger plastic deformation zone [25]. Before the sample fracture, the crack first propagates through the plastic deformation zone. Thus, the larger plastic deformation zone may lead to the higher energy consumption. The hardness of the T92 heat-resistant steel decreases with increasing tempering temperature, and thus the sample tempered at a higher temperature has a higher impact energy.

The strengthening mechanisms of the T92 heat-resistant steel can be quantitatively explained by the stresses calculated from the following equations as described in References $[20,26,27]$ :

$$
\begin{gathered}
\sigma_{\mathrm{y}}=\sigma_{0}+\sigma_{\mathrm{s}}+\sigma_{\mathrm{d}}+\sigma_{\mathrm{p}}+\sigma_{\rho} \\
\sigma_{\mathrm{d}}=k d^{-1 / 2} \\
\sigma_{\mathrm{p}}=0.8 M G b / \lambda_{\mathrm{i}} \\
\sigma_{\rho}=\alpha G b \rho^{1 / 2}
\end{gathered}
$$

where $\sigma_{\mathrm{y}}$ is the yield strength of the materials. $\sigma_{0}$ is the friction stress, and the value for pure iron is $82.5 \mathrm{MPa}$ [14]. $\sigma_{\mathrm{s}}$ is the solid solution strengthening, which can be neglected due to the high tempering temperature and the low carbon content according to Reference [14]. $\sigma_{\mathrm{d}}$ is the grain boundary strengthening related to the effective grain size $d$, where the mean block width instead of PAG size is taken to be the $d$ value according to Reference [14]. Morito et al. [28] indicated that usually three blocks are contained in one packet in low-carbon $(0.0026-0.38 \% \mathrm{C})$ steels, and the width of the blocks can be estimated by the width of the packets. $k$ is the Hall-Petch slope and for blocks the value is $390.6 \mathrm{MPa} / \mu \mathrm{m}^{1 / 2}$ [27]. $\sigma_{\mathrm{p}}$ is the dispersion strengthening, which is inversely proportional to the mean spacing of the particles $\lambda_{i} . M, G$, and $b$ are the Taylor factor (=3), the shear modulus (80 GPa at room temperature), and the length of the Burgers vector $(0.25 \mathrm{~nm})$, respectively. $\sigma_{\rho}$ is the dislocation strengthening and it is proportional to the square root of the dislocation density in the material, and $\alpha$ is a constant $(=0.88)$.

The results of the carbides hardening, block hardening, dislocation hardening, and the combined strength $\left(\sigma_{0}+\sigma_{\mathrm{d}}+\sigma_{\mathrm{p}}+\sigma_{\rho}\right)$ after tempering at different temperatures, calculated through the equations above, are shown in Figure 9. Though the calculated strength was higher than the yielding strength measured, they had the similar variation tendency with tempering temperature. This indicated that the assumptions made for the calculations were feasible and reasonable. The higher calculated strength has also been reported in Reference [14]. This was because the interactions between the various strengthening mechanisms were neglected. As shown in Figure 9, all of the three strengthening factors decreased with the increasing tempering temperature, and the rate of decline slowed down in the range of $790{ }^{\circ} \mathrm{C}$ to $815^{\circ} \mathrm{C}$. The yield strength values of the samples tempered at $715^{\circ} \mathrm{C}$ and $815^{\circ} \mathrm{C}$ were 816 and $518 \mathrm{MPa}$, respectively, with a disparity of nearly $300 \mathrm{MPa}$. The gaps of the calculated carbides hardening, block hardening, and dislocation hardening strength between the two samples were about 216, 44, and $14 \mathrm{MPa}$, respectively. The change of dislocation density had very little effect on the yield strength, which was the reason why the yield strength was not affected in the same proportion as elongation by the reduction of dislocation density in the stage of $740{ }^{\circ} \mathrm{C}$ and $760{ }^{\circ} \mathrm{C}$. According to the calculation results, it was obvious that the coarsening of $\mathrm{M}_{23} \mathrm{C}_{6}$ precipitates was the most important reason for the decrease in the RT yield strength. The size of the particles in materials was found to have a remarkable influence on the deformation performance of the material [29]. The ductile fracture process will start from the large particles and end with the linkages between the voids around the large particle [30]. The interfacial strength between the particles and the matrix influences the void nucleation and has a size dependence [31]. The coarsening of the martensite laths and reduction of 
dislocation density of the T92 heat-resistant steel tempered at higher temperature had less effects on the RT tensile performance compared to the growth of carbide precipitates.

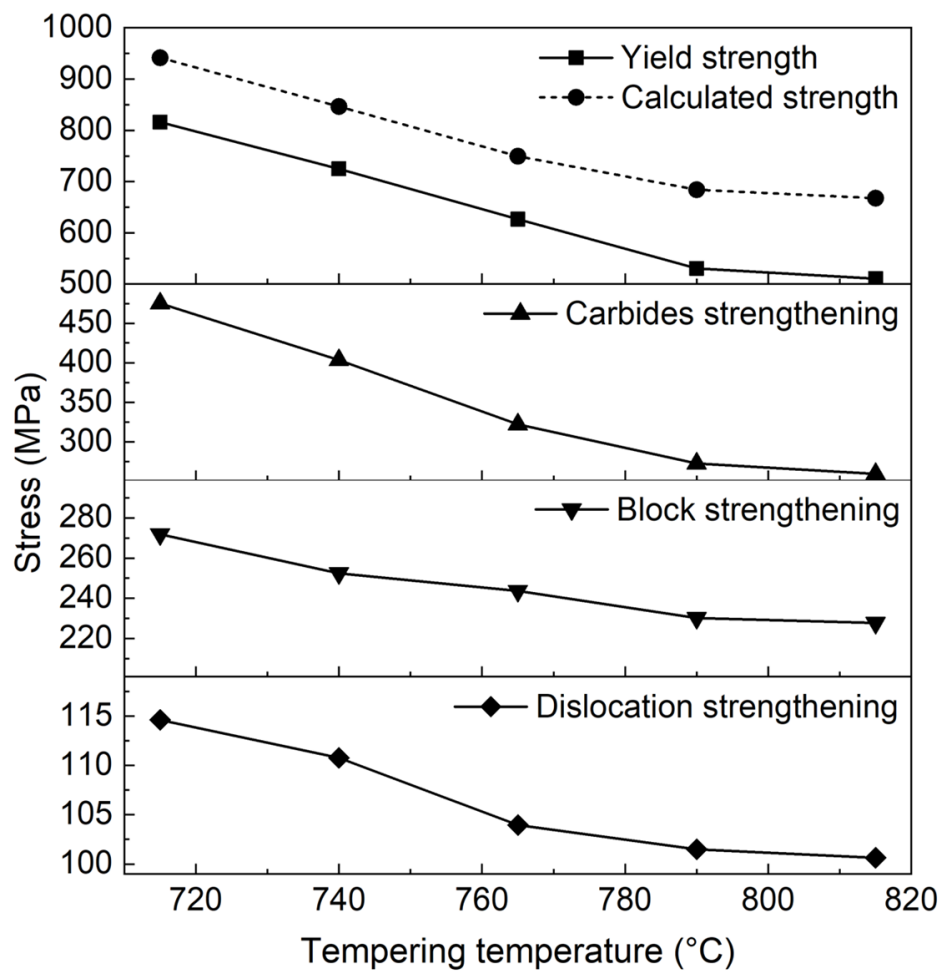

Figure 9. Contributions of the various strengthening mechanisms to the RT yield strength of the T92 heat-resistant steel tempered at different temperatures.

\section{Conclusions}

Both the microstructure and the mechanical properties of the T92 heat-resistant steel have a strong dependence on the tempering temperature. Coarsening of the martensite laths, reduction of dislocation density, and growth of carbides precipitates were observed in the samples tempered at higher temperatures. The T92 steel tempered at higher temperature showed a lower Vickers hardness due to the reduction of dislocation density. Impact energy of the T92 steel increased with increasing tempering temperature. Both the yield strength and the tensile strength of the T92 steel were lowered for the samples tempered at a higher temperature, while the elongation increased with the increasing tempering temperature. Coarsening of the carbides precipitates was considered to be the dominant factor responsible for the reduction of yield strength. Understanding the influence of tempering temperature on the T92 steel has important guiding significance for optimizing its industrial production parameters, and the effects of other heat treatment parameters should also be fully investigated in future research.

Author Contributions: X.W. and Y.W. designed the research project; D.Z. and S.Z. performed the experiments; D.Z. and H.Z. analyzed the data and wrote the manuscript; all the authors contributed to the discussions and commented on the manuscript.

Funding: This research was funded by "National Key R\&D Program of China (Grant No. 2017YFB0305203)". This research was also supported by the "National Natural Science Foundation of China (Grant No. 51601013)" and the "State Key Laboratory for Advanced Metals and Materials (Grant No. 2018Z-25)".

Acknowledgments: This work was financially supported by National Key R\&D Program of China (Grant No. 2017YFB0305203). This work was also supported by the National Natural Science Foundation of China (Grant No. 51601013) and the State Key Laboratory for Advanced Metals and Materials (Grant No. 2018Z-25).

Conflicts of Interest: The authors declare no conflict of interest. 


\section{References}

1. Zhao, L.; Jing, H.; Xu, L.; Han, Y.; Xiu, J. Analysis of creep crack growth behavior of P92 steel welded joint by experiment and numerical simulation. Mater. Sci. Eng. A 2012, 558, 119-128. [CrossRef]

2. Cheon, J.S.; Lee, C.B.; Lee, B.O.; Raison, J.P.; Mizuno, T.; Delage, F.; Carmack, J. Sodium fast reactor evaluation: Core materials. J. Nucl. Mater. 2009, 392, 324-330. [CrossRef]

3. Murty, K.L.; Charit, I. Structural materials for Gen-IV nuclear reactors: Challenges and opportunities. J. Nucl. Mater. 2008, 383, 189-195. [CrossRef]

4. Wu, Z.; Zhang, X.; Song, X.; Ma, C.; Qi, Y.; Chen, X. Microstructure and properties of welded joint for T92 ferritic heat resistant steel. J. Alloys Compd. 2017. [CrossRef]

5. Rajesh Kannan, P.; Muthupandi, V.; Arivazhagan, B.; Devakumaran, K. Microstructure and mechanical properties of heat-treated T92 martensitic heat resistant steel. High Temp. Mater. Processes 2017, 36, 771-778. [CrossRef]

6. Zhao, D.; Li, S.; Wang, Y.; Liu, F.; Wang, X. Investigation of ion irradiation hardening behaviors of tempered and long-term thermal aged T92 steel. J. Nucl. Mater. 2018, 511, 191-199. [CrossRef]

7. Guo, X.; Gong, J.; Jiang, Y.; Rong, D. The influence of long-term aging on microstructures and static mechanical properties of P92 steel at room temperature. Mater. Sci. Eng. A 2013, 564, 199-205. [CrossRef]

8. Nie, M.; Zhang, J.; Huang, F.; Liu, J.; Zhu, X.; Chen, Z.; Ouyang, L. Microstructure evolution and life assessment of $\mathrm{T} 92$ steel during long-term creep. J. Alloys Compd. 2014, 588, 348-356. [CrossRef]

9. Fedoseeva, A.; Dudova, N.; Kaibyshev, R.; Belyakov, A. Effect of Tungsten on Creep Behavior of 9\%Cr-3\%Co Martensitic Steels. Metals 2017, 7, 573. [CrossRef]

10. Vivas, J.; Capdevila, C.; Jimenez, J.; Benito-Alfonso, M.; San-Martin, D. Effect of ausforming temperature on the microstructure of G91 steel. Metals 2017, 7, 236. [CrossRef]

11. Heo, H.; Kim, J.; Kim, S.; Kim, J. Evaluation of workability on the microstructure and mechanical property of modified $9 \mathrm{Cr}-2 \mathrm{~W}$ steel for fuel cladding by cold drawing process and intermediate heat treatment condition. Metals 2018, 8, 193. [CrossRef]

12. Chen, J.; Ning, B. Research status of microstructure evolution and strengthening methods of P92 steel in the process of high temperature creep. Mater. Rev. 2014, 28, 53-59. (In Chinese) [CrossRef]

13. Totten, G.E. Steel Heat Treatment: Metallurgy and Technologies; CRC Press: Boca Raton, FL, USA, 2006; p. 22.

14. Yan, P.; Liu, Z.; Bao, H.; Weng, Y.; Liu, W. Effect of normalizing temperature on the strength of 9Cr-3W-3Co martensitic heat resistant steel. Mater. Sci. Eng. A 2014, 597, 148-156. [CrossRef]

15. Wang, S.; Peng, D.; Chang, L.; Hui, X. Enhanced mechanical properties induced by refined heat treatment for 9Cr-0.5Mo-1.8W martensitic heat resistant steel. Mater. Des. 2013, 50, 174-180. [CrossRef]

16. Liu, J.; Shu, G.; Wang, Z.; Liu, S.; Cheng, H.; Shi, C. Optimization of heat treatment process parameters for 9Cr-1Mo-V-Nb-N steel pipe. Heat Treat. Met. 2003, 28, 37-41. (In Chinese) [CrossRef]

17. Renzetti, R.A.; Sandim, H.R.Z.; Bolmaro, R.E.; Suzuki, P.A.; Möslang, A. X-ray evaluation of dislocation density in ODS-Eurofer steel. Mater. Sci. Eng. A 2012, 534, 142-146. [CrossRef]

18. Wang, L.; Li, M.; Almer, J. Investigation of deformation and microstructural evolution in Grade 91 ferritic-martensitic steel by in situ high-energy X-rays. Acta Mater. 2014, 62, 239-249. [CrossRef]

19. Li, M.; Wang, L.; Almer, J.D. Dislocation evolution during tensile deformation in ferritic-martensitic steels revealed by high-energy X-rays. Acta Mater. 2014, 76, 381-393. [CrossRef]

20. Abe, F. Precipitate design for creep strengthening of $9 \% \mathrm{Cr}$ tempered martensitic steel for ultra-supercritical power plants. Sci. Technol. Adv. Mater. 2008, 9, 13002. [CrossRef]

21. Sánchez Egea, A.J.; González Rojas, H.A.; Celentano, D.J.; Jorba Peiró, J. Mechanical and metallurgical changes on 308L wires drawn by electropulses. Mater. Des. 2016, 90, 1159-1169. [CrossRef]

22. Zhang, C.; Wang, Q.; Ren, J.; Li, R.; Wang, M.; Zhang, F.; Yan, Z. Effect of microstructure on the strength of 25CrMo48V martensitic steel tempered at different temperature and time. Mater. Des. 2012, 36, 220-226. [CrossRef]

23. Wang, L.; Li, M.; Almer, J. In situ characterization of Grade 92 steel during tensile deformation using concurrent high energy X-ray diffraction and small angle X-ray scattering. J. Nucl. Mater. 2013, 440, 81-90. [CrossRef]

24. Sánchez Egea, A.J.; González Rojas, H.A.; Celentano, D.J.; Jorba Perió, J.; Cao, J. Thermomechanical analysis of an electrically assisted wire drawing process. J. Manuf. Sci. Eng. 2017, 139, 111017. [CrossRef] 
25. Luo, Y.; Peng, J.; Wang, H.; Wu, X. Effect of tempering on microstructure and mechanical properties of a non-quenched bainitic steel. Mater. Sci. Eng. A 2010, 527, 3433-3437. [CrossRef]

26. Morito, S.; Yoshida, H.; Maki, T.; Huang, X. Effect of block size on the strength of lath martensite in low carbon steels. Mater. Sci. Eng. A 2006, 438-440, 237-240. [CrossRef]

27. Wang, C. Study on Control Unit of Strength and Toughness Microstructure of Low Alloy Martensite Steel. Ph.D. Thesis, Central Iron and Steel Research Institute, Beijing, China, May 2008.

28. Morito, S.; Tanaka, H.; Konishi, R.; Furuhara, T.; Maki, T. The morphology and crystallography of lath martensite in Fe-C alloys. Acta Mater. 2003, 51, 1789-1799. [CrossRef]

29. Sabirov, I.; Kolednik, O. The effect of inclusion size on the local conditions for void nucleation near a crack tip in a mild steel. Scr. Mater. 2005, 53, 1373-1378. [CrossRef]

30. Shabrov, M.N.; Needleman, A. An analysis of inclusion morphology effects on void nucleation. Model. Simul. Mater. Sci. Eng. 2002, 10, 163-183. [CrossRef]

31. Pan, X.; Wu, X.; Chen, X.; Mo, K.; Almer, J.; Haeffner, D.R.; Stubbins, J.F. Temperature and particle size effects on flow localization of $9-12 \% \mathrm{Cr}$ ferritic/martensitic steel by in situ X-ray diffraction and small angle scattering. J. Nucl. Mater. 2010, 398, 220-226. [CrossRef]

(C) 2019 by the authors. Licensee MDPI, Basel, Switzerland. This article is an open access article distributed under the terms and conditions of the Creative Commons Attribution (CC BY) license (http://creativecommons.org/licenses/by/4.0/). 